\title{
A DISPUTA PELO SENTIDO NOS TRIBUNAIS: ESTRATÉGIAS ARGUMENTATIVAS EM NARRATIVAS DE ALEGAÇÕES FINAIS DA ACUSAÇÃO E DA DEFESA
}

\author{
Carla Leila Oliveira Campos* \\ Universidade Federal de Alfenas \\ Instituto de Ciências Sociais Aplicadas (ICSA) \\ Varginha, MG, Brasil \\ Sara Sophia Oliveira Vieira ${ }^{\star *}$ \\ Centro Universitário Presidente Tancredo de Almeida Neves \\ São João del-Rei, MG, Brasil
}

\begin{abstract}
Resumo: O presente artigo tem o objetivo de analisar as técnicas de persuasão adotadas por acusação e defesa em suas alegações finais, em um processo de tráfico de drogas. As interações nos tribunais são altamente competitivas, e o uso dessas técnicas argumentativas visa não somente à apresentação de uma narrativa coerente e convincente, também ao ataque à narrativa da outra parte, buscando persuadir o magistrado a tomar determinada decisão. Com base nos estudos da Linguística Forense (COULTHARD; JOHNSON, 2007; GIBBONS, 2003; ROSULEK, 2010), a análise apresentada organiza-se em torno da identificação das estratégias argumentativas adotadas pelas partes (análise linguística) e da compreensão de como as narrativas se relacionam com a realidade primária dos tribunais, considerando as condições de produção do discurso e o contexto sócio-histórico de sua emergência.
\end{abstract}

Palavras-chave: Argumentação. Linguística Forense. Narrativa. Processo criminal. Alegações finais.

1 INTRODUÇÃO

Não há dúvida de que o judiciário é uma instituição de grande influência social, pois não só cria e edita normas de conduta, impondo direitos e obrigações, como também julga e busca punir comportamentos que vão contra as normas impostas nos dispositivos legais. Considerando, portanto, o poder das instituições jurídicas nas sociedades, Gibbons (2003, p. 55) argumenta que as leis são as mais linguísticas das instituições, pois são codificadas em linguagem e fundamentadas em conceitos que são acessíveis apenas pela linguagem. Além disso, os processos legais, as audiências judiciais, os interrogatórios policiais se desenrolam por meio da linguagem.

\footnotetext{
* Professora da Universidade Federal de Alfenas (UNIFAL-MG). Doutora em Estudos Linguísticos pela Universidade Federal de Minas Gerais (UFMG). E-mail: carlalcampos@globo.com

** Acadêmica do curso de Direito do Centro Universitário Presidente Tancredo de Almeida Neves (UNIPTAN). Bolsista de Iniciação Científica da Fundação de Amparo à Pesquisa do Estado de Minas Gerais (FAPEMIG). E-mail: saraestudadireito@ hotmail.com.
} 
Nesse sentido, o autor conclui que não é só a lei que permeia nossas vidas, mas a linguagem da lei.

Com fundamento nessas questões e entendendo que os assuntos levados ao judiciário, na maioria das vezes, são objeto de conflito, envolvendo, no mínimo, duas versões dos fatos, podemos afirmar que a linguagem da lei não é isenta de problemas e de disputas pelo poder. Como, aliás, qualquer forma de uso da língua não o é.

É com base nessas constatações iniciais que propomos o presente trabalho, cujo objetivo é verificar como se dá a disputa pelo sentido nos tribunais nas alegações finais de um processo criminal de tráfico de drogas, observando as técnicas de persuasão (a serem apresentadas no tópico seguinte) adotadas pelas partes (acusação e defesa) na construção de suas narrativas sobre os fatos.

Como marco teórico, inscrevemos nosso trabalho no campo da Linguística Forense, mais especificamente da análise do discurso forense, cujos estudos visam associar a análise das propriedades internas do texto às regras interacionais dos tribunais e às condições sócio-históricas de sua emergência.

Considerando o contexto e as regras de interação nos tribunais, podemos afirmar que os gêneros ${ }^{1}$ produzidos nesse espaço lançam mão, constantemente, das narrativas como forma de reconstrução dos eventos sociais e também enquanto estratégia argumentativa a favor da naturalização de determinada versão dos fatos. É com base na importância das narrativas como estratégia de construção de evidências, que nos propomos a analisá-las em nosso trabalho.

Nesse sentido, considerando o objetivo traçado, este artigo será dividido em duas partes. Num primeiro momento, faremos a exposição do quadro teórico-metodológico de abordagem do corpus. Posteriormente, apresentaremos nossa análise com base na teoria delineada.

\section{PRESSUPOSTOS TEÓRICOS E METODOLÓGICOS}

A linguística forense, segundo Gibbons (2003, p. 194), debruça-se sobre as relações entre língua e lei, podendo envolver o estudo da interpretação e da tradução da lei, das desvantagens produzidas pela língua nos tribunais, da linguagem da lei em documentos, audiências, delegacias, processos etc. e também a produção de evidências linguísticas forenses.

Nesse sentido, podemos afirmar que a linguística forense cuida da análise da linguagem relacionada à lei, seja como evidência, seja como discurso legal (OLSSON; LUCHJENBROERS, 2013). Nesta segunda vertente, os trabalhos em linguística forense, associados a teorias do discurso, têm o intuito de compreender como as funções institucionais específicas estão relacionadas aos usos da língua, analisando a interseção

\footnotetext{
${ }^{1}$ Adotamos aqui a perspectiva sociodiscursiva de gênero influenciada pelos estudos de Mikhail Bakhtin, pelas teorias do texto e do discurso e pelos estudos da enunciação linguística. No Brasil, essa perspectiva é desenvolvida por Marcuschi (2005), para quem os gêneros textuais são textos materializados em nossa vida diária e que apresentam características sociocomunicativas definidas por seus conteúdos temáticos; propriedades funcionais; estilo verbal e construção composicional.
} 
entre o discurso institucional, a lei e os significados sociais (COULTHARD; JOHNSON, 2007, p. 7).

A análise do discurso forense deve, portanto, associar a produção linguística no interior da prática jurídica e os valores sociais e institucionais, envolvendo questões relacionadas aos papéis sociais desempenhados pelos sujeitos em determinada situação de comunicação e ao modo como esses papéis determinam o que eles podem/devem ou não dizer, as limitações institucionais impostas ao discurso e a forma como os valores sociais interferem na produção discursiva.

O discurso jurídico é um tipo bastante peculiar de discurso, pois os gêneros textuais produzidos no âmbito forense possuem uma relação necessária com o sistema de normas jurídicas que regem determinada sociedade. É esse sistema de normas que regula as práticas linguísticas, determinando o que é juridicamente relevante. Além disso, não podemos perder de vista, conforme afirma Gibbons (2003, p. 53), que a própria lei representa um sistema de valor social, impondo direitos e deveres, prescrevendo e punindo comportamentos que forem de encontro às normais sociais.

Todavia, não podemos deixar de destacar que o discurso jurídico não sofre influência apenas do sistema legal, mas do sistema de valores que circula em determinada sociedade e do sistema sociocultural dos participantes da atividade comunicativa.

Outra característica marcante dos textos que materializam o discurso jurídico, especialmente aqueles produzidos nos tribunais, é o seu caráter competitivo e, por isso, argumentativo, já que o intuito das partes litigantes é sempre convencer e persuadir ${ }^{2}$ seu interlocutor acerca da verossimilhança de sua versão dos fatos. Além disso, ao mesmo tempo em que busca levar o outro a acreditar em sua versão dos fatos, o locutor precisa atacar a versão da parte contrária, mostrando sua insuficiência ou incoerência.

Nesse sentido, as narrativas produzidas nos tribunais assumem um papel primordial na condução e análise dos litígios, revestindo-se de forte caráter argumentativo ${ }^{3}$, pois é a partir delas que os magistrados tomam suas decisões.

Corroborando essa afirmação, Henderson (2015, p. 3) afirma que na escrita jurídica a narrativa é um elemento integrante da argumentação legal:

\footnotetext{
De forma geral, [...] a narrativa é crucial para a tomada de decisão legal, pois a tarefa primária do juiz é construir uma história plausível e coerente a partir de um dado caso. Assim, o ângulo de visão a partir do qual a história é contada (perspectiva narrativa) tem um impacto na decisão tomada. ${ }^{4}$
}

\footnotetext{
${ }^{2}$ De acordo com Henriques (2008, p. 37), “convencer e persuadir são atos perlocucionários. Convencer é o primeiro passo, o érgon, tem por objetivo esclarecer, fazer compreender, conscientizar. Persuadir é um passo a mais, a enérgeia, que leva ao ato, ao resultado e tem por objetivo conduzir, levar ao fazer".

${ }^{3}$ Neste trabalho, interessa-nos a noção de argumentação que considera "argumentativos os discursos que expõem e amplificam o desacordo, [...] que visam a mostrar as polêmicas" (FIORIN, 2016, p. 28), marca bastante evidente nos gêneros jurídicos que envolvem os debates. Não estamos afirmando, é claro, que não reconheçamos a natureza dialógica do discurso, segundo a qual "todos os discursos são argumentativos, pois são uma reação responsiva a outros discursos.” (FIORIN, 2016, p. 29).

${ }^{4}$ Tradução livre de: In a more general sense, [...] narrative is crucial to legal decision-making because the primary task of the judge is to make a plausible and coherent story out of a given case. Thus the angle of vision from which the story is told (narrative perspective) and the language and the style in which it is couched (narrative voice) have an impact in the decision arrived at. (HENDERSON, 2015, p. 3).
} 
Devido a sua relevância jurídica para o convencimento do magistrado e, consequentemente, para sua tomada de decisão, as narrativas estão presentes na maioria dos gêneros forenses e são utilizadas pelos profissionais do direito com o intuito de naturalizar determinada versão dos eventos. Assim, devemos sempre levar em consideração que as narrativas que chegam aos tribunais são valoradas (VALVERDE; FETZNER; TAVARES JÚNIOR, 2013), ou seja, os fatos foram analisados e selecionados de acordo com os interesses comunicativos das partes:

\begin{abstract}
Não podemos perder de vista que essa seleção de o que é ou não relevante dependerá do interesse que o profissional está representando no processo. Em outras palavras, o que parece relevante para a parte autora pode não ser assim compreendido pela parte ré. (VALVERDE; FETZNER; TAVARES JÚNIOR, 2013, p. 49).
\end{abstract}

Citando Hale e Gibbons (1999), Gibbons (2003) afirma que o discurso nos tribunais envolve a relação entre duas realidades que estão em constante interação: uma realidade primária, formada pelo tribunal e pelas pessoas nele presentes e uma realidade secundária, formada pelos eventos que são objeto de litígio.

Como os eventos da realidade secundária estão distantes da realidade primária no tempo e no espaço, eles precisam ser representados. Essa representação pode se dar mediante evidências reais (fotos, gravações etc.), mas, na maioria das vezes, acontece por meio da reconstrução narrativa dos fatos. Como vimos anteriormente, é a partir dessas narrativas que o juiz toma sua decisão com base na narrativa que julgar mais convincente em termos de completude, consistência e credibilidade das testemunhas (GIBBONS, 2003).

Considerando o caráter essencialmente argumentativo das narrativas produzidas nos tribunais, Gibbons (2003, p. 92), citando Jackson (1988), ressalta que, além do conteúdo semântico dessas narrativas, os trabalhos de análise devem se debruçar à pragmática dessas histórias (o processo de persuasão da audiência de que essas histórias são verdadeiras).

É com base nessa afirmação de Gibbons, especialmente em relação à pragmática das narrativas forenses, que propomos o presente trabalho. Nosso intuito será, portanto, verificar quais são as técnicas argumentativas adotadas por acusação e defesa em suas alegações finais, com o objetivo não só de apresentar uma narrativa coerente e convincente, mas também de atacar a narrativa da outra parte, buscando persuadir o interlocutor - no caso, o magistrado - a tomar determinada decisão. Para isso, além da identificação das estratégias persuasivas adotadas pelas partes (análise linguística), buscaremos compreender como essas narrativas se relacionam com a realidade primária dos tribunais, considerando as condições de produção do discurso.

A análise dessa dimensão interacional é fundamental, pois, de acordo com Gibbons (2003, p. 96), para compreendermos a interação humana, precisamos entender os quadros nos quais ela opera, as condições e regulações externas que a cercam e contribuem para a construção de seu significado.

Como nosso objetivo é o estudo de processos, vejamos, portanto, algumas características do processo criminal no Direito Penal brasileiro. O processo criminal consiste no método adotado pelo Estado "para a solução de conflitos decorrentes do 
desrespeito às leis penais" (BRENTEL, 2012, p. 23) e tem como objetivos promover a pacificação social, proteger os direitos das partes e coibir comportamentos que vão de encontro à ordem social e ao bem comum, mediante a aplicação de sanções.

O processo penal brasileiro é organizado nas seguintes fases: a) inquisitiva ou postulatória: a polícia investiga o crime, elabora o inquérito apresentando as provas e depoimentos do autor e das testemunhas e envia ao juiz; b) instrutória ou probatória: após autorização do juiz, o Promotor de Justiça ${ }^{5}$ analisa o processo e decide se vai ou não oferecer a denúncia contra o acusado. Oferecida a denúncia, o juiz decide se vai recebêla ou rejeitá-la. Recebendo-a, o réu é citado para apresentar resposta escrita à acusação e dá-se prosseguimento ao processo por meio da realização da audiência de instrução e julgamento, sendo produzidos os termos de audiência. Ao fim da instrução processual, a acusação e a defesa apresentam suas alegações finais e, após análise dessas peças, o juiz produz a sentença; c) fase executória: execução da sentença com trânsito em julgado.

Considerando que o objetivo de nosso trabalho é verificar como se dá a disputa pelo sentido nos tribunais, observando as técnicas de persuasão adotadas pelas partes (acusação e defesa) na construção de suas narrativas sobre os fatos, serão objeto de nossa análise neste trabalho as alegações finais da acusação e da defesa, por considerar que elas são importantes peças do processo penal, pois são produzidas após o andamento processual, trazendo um resumo (parcial, é claro) dos fatos levantados durante todo o andamento do processo, e por servirem de base para a decisão do magistrado.

As alegações finais são, portanto, o momento em que as partes apresentam suas versões finais do caso, enfatizando não só a credibilidade dessa versão como também a falsa percepção da versão da outra parte. Nelas, segundo Rosulek (2010), o advogado fala diretamente a quem pretende convencer, sem interagir com as testemunhas. Nesse sentido, as alegações finais ficam livres de influências externas que podem afetar o discurso.

Para a autora, a importância de se tomar as alegações finais como objeto de análise deve-se ao fato de que

\begin{abstract}
Durante as alegações finais, dois falantes tomam a mesma pessoa, os mesmos eventos e evidências e criam duas representações opostas para a mesma audiência. Compreender como isso ocorre pode revelar como os objetivos e crenças dos falantes afetam seu uso da linguagem. Além disso, esses discursos são ambos persuasivos e argumentativos, fornecendo, portanto, uma excelente oportunidade para estudar como são linguisticamente construídos. (ROSULEK, 2010, p. 218). ${ }^{6}$
\end{abstract}

Para realizar a análise linguística das narrativas, adotaremos como categorias de análise as técnicas de persuasão propostas em Coulthard e Johnson (2007) - o enquadramento das narrativas nos sistemas legais; o ataque ao testemunho, que pode se

\footnotetext{
${ }^{5}$ A denúncia é a peça oferecida pelo Promotor de Justiça quando tratar-se de ação penal pública, que é o caso de nosso trabalho. Há também a possibilidade de o processo se dar por iniciativa privada, quando um advogado apresenta a Queixa-crime contra o réu.

6 Tradução livre de: "During the closing arguments, two speakers take the same people, events, and evidence, and create two opposing representations for the same audience. Understanding how this occurs can reveal how speakers' goals and belief systems affect their use of language. Additionally, these discourses are both persuasive and argumentative, thus providing a prime opportunity to study how such discourses are linguistically created."
} 
dar por meio do ataque ao conteúdo do que é dito ou à credibilidade (pessoa) da testemunha; as escolhas lexicais como o uso de determinados verbos e adjetivos etc. - e aquelas propostas por Rosulek (2010) - a negociação da imagem e do relacionamento; a produção de evidências; a recontextualização ou reinterpretação dos dizeres das testemunhas; o apagamento de fatos ou de vozes que sustentam o outro lado da história além de uma técnica, não descrita por esses autores, mas identificada em nosso corpus, a valorização da testemunha.

No que tange à influência das regras de interação na produção discursiva, é importante atentarmos para a seguinte posição de Caldas-Coulthard (2008, p. 37):

\begin{abstract}
Todos os textos têm contextos, e mesmo que estejamos analisando apenas aspectos linguísticos, temos que estar cientes do que está informando o texto fora dele e afetando sua maneira de produção. Por exemplo, quem escreveu o texto, para quem o texto é escrito, quando onde e por que foi escrito? Onde o texto apareceu e em que formato?
\end{abstract}

Para isso, apresentamos algumas considerações sobre as regras de interação nos tribunais. Inicialmente, precisamos reconhecer que, de modo geral, essas interações são altamente hierárquicas e autoritárias. Nesse aspecto, é necessário compreender as relações de poder entre os participantes da interação e como elas influenciam a linguagem. Além disso, há que se considerar, nesta fase da análise, os papéis sociais desempenhados pelos participantes da interação, seus propósitos comunicativos e como tudo isso se reflete na linguagem.

Ademais, como o discurso jurídico não é alheio a seu tempo, procuraremos compreender como as narrativas criadas pelas partes ligam-se a outras narrativas que circulam em nossa sociedade, apelando para crenças sociais e culturais para produzir um cenário no qual forças sociais de poder atuam nos sujeitos da interação combinando histórias dentro do julgamento que eles próprios trazem para o tribunal como cidadãos constituídos e construídos socialmente (COULTHARD; JOHNSON, 2007, p. 101).

\title{
3 ANÁLISE DO CORPUS
}

Exposto o quadro teórico e metodológico no qual inscrevemos o presente trabalho, passemos agora à análise das alegações finais do Ministério Público (acusação) e da Defensoria Pública (defesa). Em relação à escolha das alegações finais, como dito anteriormente, tal opção se deve a sua importância na fase processual, pois é a última peça da fase de instrução, na qual as partes (acusação e defesa) analisam as ocorrências processuais, buscando influir na decisão do magistrado, que será proferida logo após a apreciação das alegações.

Os resultados de nossa análise serão apresentados na seguinte ordem: em um primeiro momento, apresentaremos algumas considerações sobre as regras de interação e os papéis assumidos pelas partes, com o objetivo de verificar como essas regras e papéis determinam as escolhas linguísticas e o conteúdo de seus dizeres; em uma segunda fase, verificaremos, à luz das categorias descritas no item anterior, como cada uma das partes trabalha seus textos no intuito de defender sua versão narrativa dos fatos e, ao mesmo 
tempo, atacar a narrativa oposta; ao longo da análise linguística, teceremos comentários acerca da relação que essas narrativas mantêm com outras narrativas que circulam em nossa sociedade, especialmente acerca da imagem do crime de tráfico de drogas.

As peças que são objeto de nossa análise são componentes de um processo penal de tráfico de drogas no qual o réu, R.C.S. ${ }^{7}$, maior, foi apreendido juntamente com um menor, S.L., portando aquele, segundo testemunho dos dois policiais (Policial R e Policial F) que realizaram a ocorrência, oito invólucros plásticos contendo cocaína. Segundo os policiais, eles se dirigiram ao local da apreensão após denúncias de tráfico de drogas na região e, ao chegarem lá, surpreenderam o menor e R.C.S em atitude suspeita. O Policial $\mathrm{R}$ afirma que, ao avistar a viatura, R.C.S. jogou a droga que estava em sua posse no chão. Já o Policial F declara que não viu quem jogou a droga. O menor assumiu ser dono dos entorpecentes e o R.C.S. afirma ser usuário e que estava no local para comprar drogas do menor. Nesse sentido, o inquérito policial foi elaborado com base nos depoimentos dos policiais que realizaram a ação, do próprio R.C.S. e do menor, acompanhado por uma conselheira tutelar. R.C.S., então, foi denunciado pelo Ministério Público pelo crime de tráfico de drogas. Todas as testemunhas foram ouvidas também na audiência de instrução e julgamento, que antecede as alegações finais.

Como vimos anteriormente, ao se analisar os discursos que circulam no âmbito forense não podemos perder de vista os modos de interação que envolvem a produção do discurso nos tribunais. Nesse sentido, vimos que essas interações são altamente hierárquicas e autoritárias. Essas relações de poder institucionais têm reflexos na produção das peças processuais tanto da acusação quanto da defesa, pois ambas destinamse ao juiz, a quem é dado o poder de decidir sobre a inocência ou culpa do réu. Nesses termos, toda a construção linguística das peças acontece no sentido de persuadi-lo quanto à autoria/não autoria do crime de tráfico.

Além disso, outro importante fator há que ser considerado nas relações de poder presentes no processo penal. A atividade de acusação tem a seu favor o interrogatório policial e a investigação do suposto crime, cabendo ao locutor o oferecimento da denúncia com base no inquérito policial, originado da apreensão do réu e da oitiva das testemunhas e do próprio réu. Portanto, quem fala primeiro no processo, é a acusação. Já a atividade de defesa, além de não ter a seu lado a máquina estatal, constrói-se como resposta à acusação, que já determinou sobre o que se pode falar. Nesse sentido, a construção das alegações finais da defesa se dá, essencialmente, por meio da negação de fatos já levantados pela acusação, construindo-se como resposta a esta. Não cabe à defesa, portanto, trazer para a discussão fatos que se distanciem muito do tópico principal já demonstrado pela acusação. Contudo, objetivando assegurar a ampla defesa do réu, ao dar a ele o direito de se manifestar por último no processo, o Estado busca assegurar-lhe a prerrogativa de se defender de todas as acusações recebidas.

Outra característica do discurso forense é o fato de que ele se constrói a partir do sistema de leis da sociedade. No caso em comento, R.C.S. foi denunciado pela prática do

\footnotetext{
${ }^{7}$ Optamos, por questões éticas, por não fazer referência ao nome das partes, mesmo considerando que o processo é público e não corre em segredo de justiça. O réu, portanto, será denominado neste trabalho como R.C.S., o menor, S.L. e os policiais, Policial R e Policial F.
} 
crime de tráfico de drogas, encontrando-se incurso no art. 33, caput, da Lei 11.343/06, que institui o Sistema Nacional de Políticas Públicas sobre Drogas. De acordo com referido artigo, incorre em crime de tráfico o cidadão que

Importar, exportar, remeter, preparar, produzir, fabricar, adquirir, vender, expor à venda, oferecer, ter em depósito, transportar, trazer consigo, guardar, prescrever, ministrar, entregar a consumo ou fornecer drogas, ainda que gratuitamente, sem autorização ou em desacordo com determinação legal ou regulamentar:

Pena - reclusão de 5 (cinco) a 15 (quinze) anos e pagamento de 500 (quinhentos) a 1.500 (mil e quinhentos) dias-multa. (BRASIL, 2006).

Como se percebe pelos verbos presentes no caput do art. 33, a Lei 11.343/06 busca o combate ostensivo ao crime de tráfico de drogas enumerando um conjunto extenso de condutas que se configuram em crime. No intuito de procurar afastar o crime de tráfico, cabe à defesa, em sua versão dos fatos, construir a imagem do réu como usuário de drogas, revelando sua condição de vítima do vício, como veremos na análise abaixo apresentada.

Vejamos, portanto, mediante as categorias apresentadas no tópico anterior, como acusação e defesa constroem as estratégias argumentativas de suas versões dos fatos. Para cada estratégia argumentativa adotada pelos locutores apresentaremos, inicialmente, trechos das alegações finais da acusação e, posteriormente, da defesa, tecendo alguns comentários comparativos entre as versões narrativas dos fatos. Destacamos apenas que, muitas vezes, em um mesmo enunciado, encontramos diferentes estratégias argumentativas usadas simultaneamente.

3.1 ATAQUE AO TESTEMUNHO

\title{
3.1.1 ATAQUE AO CONTEÚDO DO DIZER DAS TESTEMUNHAS
}

\author{
Acusação:
}

\begin{abstract}
"O adolescente S.L., às fls. 06, assumiu a propriedade da substância entorpecente apreendida, alegando que se destinaria ao seu próprio consumo, disse que não conhecia o acusado e que não foi o mesmo que lançou a droga no chão [...] declaração esta que vai de encontro àquelas prestadas pelo denunciado e encontram-se isoladas nos autos."
\end{abstract}

\section{Defesa:}

[Cita trechos dos depoimentos dos policiais]:

Policial R: "que existem diversas ocorrências no local e denúncias efetuadas do tráfico de drogas realizado no local, sendo o S.L. 'o gerente da boca' e R.C.S. um de seus traficantes." Policial F: “[...] tanto R.C.S. como o menor S.L. já são conhecidos no meio policial por tráfico de drogas, tendo ambos já sido abordados anteriormente."

Argumento da Defesa: "pode ser que o réu seja conhecido da polícia militar. Todavia, afirmamos que tal conhecimento não se dê pela traficância como pretendem demonstrar os aludidos policiais." 
[Cita a CAC do réu, acostada aos autos, para confirmar várias anotações por violação ao artigo $28^{10}$ da Lei $\left.11343 / 06\right]$.

“Outro ponto de suma importância para a elucidação do caso em tela diz respeito à autoria daquele que em tese teria dispensado a porção de droga, no momento em que foram surpreendidos pela guarnição policial. [...] o policial R. foi categórico ao afirmar: '[...] R.C.S. jogou um embrulho de papel no chão [...].' Entretanto, outro policial militar ouvido às f. 7 , afirma que não deu para ver quem dispensou a droga.”

Nesses trechos, com o intuito de desconstruir a validade dos depoimentos testemunhais que vão de encontro a sua versão dos fatos e, ao mesmo tempo, sustentam a versão contrária, acusação e defesa lançam mão da técnica argumentativa de ataque ao testemunho, no caso, esse ataque se dá ao conteúdo do dizer dessas testemunhas.

No que tange à narrativa da acusação, objetivando levantar dúvida em relação à declaração do menor de que ele era o dono da droga e que também a lançara no chão com a chegada dos policiais, o Ministério Público procura levantar dúvidas sobre o conteúdo desse dizer, afirmando que sua afirmação vai de encontro às declarações prestadas pelo réu R.C.S. na fase inquisitorial do processo, nas quais assumiu a posse dos entorpecentes.

A defesa, por sua vez, utiliza-se desta técnica argumentativa em três momentos. Primeiramente, para contestar as afirmações dos dois policiais - responsáveis pela prisão do réu e testemunhas no processo - de que o réu é conhecido da polícia pelo tráfico de drogas, ataca seus testemunhos por meio da apresentação da Certidão de Antecedentes Criminais (CAC) de R.C.S., que serve como prova documental para enquadrar a conduta do réu no artigo 28 da Lei 11.343/06, que se refere ao porte de drogas para uso. A apresentação da CAC do réu para atacar a veracidade do dizer das testemunhas, antecipa outra estratégia argumentativa que veremos abaixo, no caso, a apresentação de evidências para questionar um dizer, já que, como vimos, os documentos são meios de prova no processo. Nesse sentido, ao contestar o dizer das testemunhas por meio de uma prova documental, a defesa utiliza-se de uma estratégia argumentativa quase irrefutável.

No segundo trecho acima destacado, a defesa ataca o dizer dos policiais, principais testemunhas no processo, destacando a contradição entre o que é afirmado por um deles - que diz categoricamente que o réu jogou o embrulho de papel no chão - e pelo outro que declara que não foi possível ver quem dispensou a droga - gerando dúvidas acerca da certeza alegada pelo policial $R$.

\title{
3.1.2 ATAQUE À CREDIBILIDADE DAS TESTEMUNHAS
}

\author{
Acusação:
}

“[...] em que pese a negativa de autoria do réu [...], este, quando dos fatos, se comportava de maneira suspeita, além do que existiam notícias acerca do seu envolvimento no comércio de

\footnotetext{
${ }^{10} \mathrm{O}$ art. 28 da Lei 11.343/06 elenca as penas aplicáveis para "quem adquirir, guardar, tiver em depósito, transportar ou trouxer consigo, para consumo pessoal, drogas sem autorização ou em desacordo com determinação legal ou regulamentar [...]” (BRASIL, 2006).
} 
entorpecentes, razão pela qual foi realizada sua abordagem, quando então se constatou a veracidade de referidas denúncias, que culminaram com a prisão em flagrante delito do denunciado." (Grifos nossos).

“[...] não há dúvidas acerca da apreensão de drogas em poder do réu e do adolescente S.L., já conhecidos pelo envolvimento no tráfico de entorpecentes."

"[...] certo é que se tornou uma prática comum entre os adolescentes apreendidos confessar a autoria do delito para livrar seus comparsas das penas impostas, pelo que seus depoimentos devem ser analisados com ressalvas."

[Cita duas jurisprudências do TJMG para fundamentar juridicamente sua afirmação].

Defesa:

“Outro grande indício da atuação discriminatória dos policiais diz respeito ao suposto relógio de cor dourada da marca MICHAEL KORS, que era usado pelo réu no momento da prisão. Os policiais, ao avistarem o réu em um ponto de venda de drogas, usando um relógio de marca, presumiram que R.C.S. fosse o traficante. [...] Isso vem a demonstrar que o estereótipo criado pela instituição policial, foi aplicado integralmente à figura do réu." (Grifos nossos).

“[...] tornou-se patente o reconhecimento que os depoimentos prestados pelos policiais não são dignos de fidelidade como quer a acusação, ou ao menos estão ofuscados pela visão estigmatizada do 'traficante de drogas'."

“[...] seus [dos policiais] informes são no sentido de validar a ação de prisão praticada. Dessa forma, para ter validade deve ser corroborada pelas demais provas [...]”.

[Cita duas jurisprudências do TJMG fundamentar juridicamente sua tese].

Nos dois primeiros enunciados da narrativa da acusação, o locutor busca atacar a credibilidade das testemunhas - no caso, o réu e o menor que confessou ser o dono da droga apreendida -, ressaltando haver notícias acerca do envolvimento de ambos com o tráfico de entorpecentes, o que os torna conhecidos do meio policial. É interessante observarmos, também, no primeiro enunciado, como a seleção lexical (técnica argumentativa a ser explorada abaixo) contribui para o ataque à pessoa do réu pelo uso do adjetivo "suspeita", para qualificar sua conduta, e da expressão "constatou a veracidade", para validar as denúncias que, se até então eram notícias, transformam-se em fatos quando da abordagem policial. Inserindo esses enunciados no contexto sóciohistórico de sua ocorrência, vemos a relação estreita entre a narrativa da acusação e narrativas que circulam em nossa sociedade fundadas na crença de que pessoas envolvidas em algum tipo de crime, no caso, o tráfico de drogas, não merecem credibilidade.

Essa mesma análise, aplica-se ao terceiro enunciado da narrativa da acusação, que, ao procurar atacar a credibilidade do menor enquanto testemunha, ressaltando que seu depoimento deve ser analisado com ressalvas, afirma ter se tornado "uma prática comum entre os adolescentes apreendidos confessar a autoria do delito para livrar seus comparsas das penas impostas". Verifica-se, também neste trecho, que a estratégia argumentativa da 
defesa se fundamenta em crenças e narrativas que circulam em nossa sociedade acerca do envolvimento de menores em práticas de crimes orquestradas por maiores, e não propriamente em evidências do processo ou do caso em julgamento. Para confirmar essa afirmação, como já dito, mais fundamentada em crenças do que em fatos, o locutor utilizase da técnica argumentativa do enquadramento de sua narrativa nos sistemas legais, fundamentando seu dizer em trechos de decisões do Tribunal de Justiça de Minas Gerais, autoridade que assegura a validade desse dizer.

Por parte da defesa, o ataque à credibilidade das testemunhas é dirigido aos policiais que, como dito anteriormente, são as testemunhas de acusação no processo. Primeiramente, a defesa procura desconstruir a credibilidade dos policiais, afirmando que suas condutas foram guiadas pelo preconceito e não pela situação fática. Para tanto, é interessante atentarmos para as escolhas lexicais operadas pelo locutor, no intuito de avaliar o registro feito pelos policiais no Boletim de Ocorrência e em seus depoimentos sobre estar o réu utilizando um relógio que julgaram ser de ouro e da marca Michael Kors (e que no curso do processo foi provado ser uma falsificação adquirida em uma banca de camelô): a defesa afirma que essa constatação dos policiais é um "grande indício" de sua conduta "discriminatória" e que esse "estereótipo criado pela instituição policial" os levou a "presumir" (ou seja, tirar uma conclusão antecipada, baseada em presunções e não em fatos) que o réu era traficante. Aqui também vemos como a narrativa criada pela defesa está ligada a narrativas que circulam em nossa sociedade, tanto acerca da imagem que se tem do traficante quanto da instituição polícia militar. Essa imagem da polícia militar como instituição que, muitas vezes, alimenta preconceitos e estereótipos sociais é, mais uma vez, utilizada pela defesa no segundo enunciado para atacar a credibilidade dos policiais enquanto testemunhas.

Já no terceiro enunciado, o ataque à credibilidade do testemunho dos policiais se dá por seus depoimentos deverem ser vistos com ressalvas já que são no sentido de validar a prisão que praticaram. Para isso, o locutor afirma que esses depoimentos, para serem válidos, precisam ser corroborados por outras provas. Como a acusação, ao buscar valorizar o depoimento dos policiais, como veremos abaixo, apela para jurisprudências que comprovam sua tese, a defesa também cita duas decisões do Tribunal de Justiça de Minas Gerais, utilizando a técnica argumentativa de enquadramento das narrativas nos sistemas legais, com o objetivo não só de validar sua afirmação, mas, ao mesmo tempo, contrapor-se à versão da acusação.

\title{
3.2 VALORIZAÇÃO DAS TESTEMUNHAS
}

\author{
Acusação:
}

\footnotetext{
"[Policial R.], às fls. 68, além de reconhecer o acusado como sendo a pessoa que dispensou a droga no momento da diligência policial, ainda ratificou seu depoimento prestado em sede policial, no qual narrou minuciosamente todo ocorrido."

[Cita o depoimento da testemunha].
} 
“Outrossim, o [Policial F], às fls. 03 e 67, relatou ter avistado, durante o patrulhamento, o denunciado e o menor S. L. em atitude suspeita, quando um destes lançou um embrulho de papel no chão, o qual continha oito 'buchas de substância semelhante a cocaína', disse que tanto o acusado quanto o adolescente são conhecidos no meio policial por envolvimento no tráfico de drogas, já tendo, inclusive, sido abordados anteriormente."

[Não cita trecho do depoimento].

"[...] referidos testemunhos têm o mesmo valor probatório que qualquer outro colhido neste feito, não havendo elemento que os desconstitua ou desacredite, mas, ao contrário, trata-se de depoimentos de agente público, possuidores de fé-pública, que tem o compromisso legal de dizer a verdade."

“[...] inexistem dúvidas acerca da credibilidade das declarações prestadas pelos Policiais Militares referidos, já que não há qualquer elemento evidenciador de que tenham algum tipo de querela com o denunciado a denotar que queriam prejudicá-lo".

[Cita cinco jurisprudências que confirmam o valor do depoimento dos policiais militares: uma do STF, uma do STJ, três do TJMG].

\section{Defesa:}

Cita depoimento do réu no Inquérito Policial: "Que o declarante afirma ser viciado em drogas e que nesta data foi até a Rua XXX para comprar drogas, que o declarante encontrou a pessoa de S.L. e iria comprar a droga do mesmo, no momento em que os policiais chegaram ao local."

Faz menção a documentos comprobatórios (declarações de clínicas especializadas no tratamento ao vício) para confirmar esta tese (depoimento do réu).

Cita também Comunicação de Serviço da Polícia Civil que afirma que somente o menor possuía informações sobre tráfico.

Buscando a valorização dos testemunhos que confirmam sua versão dos eventos e, principalmente, porque toda a sua narrativa é construída a partir da prova testemunhal, a acusação, nos dois primeiros enunciados, retoma os depoimentos dos policiais, prestados tanto na fase inquisitorial quanto na audiência de instrução e julgamento. Contudo, em relação às técnicas utilizadas na valorização desses testemunhos, percebemos que não são idênticas. Como o depoimento do primeiro policial (Policial R) é mais interessante à acusação - por confirmar sua versão do que teria ocorrido -, além de citar, na íntegra, trechos desse depoimento, o locutor da peça opera seleções lexicais no intuito de ressaltar a certeza do policial quanto a seu dizer: "ratificou seu depoimento" e "narrou minuciosamente". Já em relação ao segundo policial (Policial F), como seus dizeres possuem uma nuance de incerteza em relação a quem atirou a droga no chão, seu depoimento não é reproduzido ipsis litteris, na narrativa da acusação, sendo apresentado apenas em discurso indireto

Já com o objetivo de contestar argumentos acerca da falta de credibilidade do depoimento de policiais militares, a acusação ressalta que, por serem funcionários públicos, são dotados de fé-pública, tendo compromisso legal com a verdade. Ainda com esse mesmo objetivo, a acusação afirma ainda que, no caso, os policiais não tinham 
qualquer tipo de "querela" com o réu, que pudesse pôr em dúvida seus depoimentos. Para confirmar seus argumentos, o locutor adota, novamente, a técnica argumentativa do enquadramento de sua narrativa nos sistemas legais, citando trechos de decisões do Supremo Tribunal Federal (STF), do Superior Tribunal de Justiça (STJ) e do Tribunal de Justiça de Minas Gerais (TJMG), que ratificam seus argumentos.

Já a defesa, buscando valorizar o depoimento do réu, desqualificado pela acusação, como vimos anteriormente, pelo seu envolvimento com o tráfico de entorpecentes, apresenta documentos comprobatórios, produzindo evidências que comprovam a veracidade de suas afirmações, com vistas a resgatar a credibilidade de seu dizer.

\title{
3.3 PRODUÇÃO DE EVIDÊNCIAS
}

Acusação:

\begin{abstract}
"A materialidade está patenteada no APFD de fls. 02/09, no boletim de ocorrência de fls. 14/20, no auto de apreensão de fls. 21, no laudo toxicológico provisório de fls. 29, no laudo toxicológico definitivo de fls. 35 e no laudo de constatação de fls. 54."
\end{abstract}

\section{Defesa:}

\footnotetext{
"Por diversas vezes, nessa persecução penal, o réu afirmou ser usuário de drogas, comprovando inclusive com Declarações de Internação em clínicas especializadas para o tratamento de dependência química."
}

Em relação à estratégia argumentativa de produção de evidências, já vimos, na análise acima apresentada, que a defesa lança mão desta técnica de persuasão por diversas vezes, ao apresentar documentos que comprovam a dependência química do réu.

$\mathrm{Na}$ narrativa da acusação, encontramos apenas no enunciado acima reproduzido o uso desta técnica argumentativa, apontando este enunciado o Boletim de Ocorrência, o Auto de Prisão em Flagrante e os laudos toxicológicos como documentos que comprovam a veracidade de sua versão narrativa dos fatos.

Já a defesa, além dos exemplos já discutidos, utiliza-se, mais uma vez, das Declarações de Internação apresentadas pelo réu para tratamento do vício em drogas, como evidências que comprovam a veracidade de sua versão dos fatos, buscando atribuir coerência à narrativa.

\subsection{ENQUADRAMENTO DAS NARRATIVAS NOS SISTEMAS LEGAIS}

\section{Defesa:}


favor do réu". Cita duas jurisprudências do TJMG para destacar impossibilidade de condenação na ausência de provas.

Para pedir a desclassificação do crime para o delito do artigo 28 da Lei 11.343/06 e a absolvição do réu, cita uma doutrina e jurisprudência do TJMG.

Tanto acusação quanto defesa já se utilizaram desta técnica argumentativa ao citarem jurisprudências que confirmavam determinadas teses sustentadas pelas partes.

Além dos exemplos já apresentados, encontramos ainda na narrativa da defesa mais dois enunciados que adotam semelhante técnica: para fundamentar a tese da presunção da inocência, cita o princípio do in dubio pro reo além de trechos doutrinários e jurisprudenciais; já para fundamentar o pedido de desclassificação do crime para o delito previsto no artigo 28, a defesa enquadra sua narrativa nos sistemas legais citando novamente a doutrina e a jurisprudência.

\title{
3.5 ESCOLHAS LEXICAIS
}

\section{Acusação:}

\begin{abstract}
"Trata-se de ação penal na qual se imputa ao denunciado em epígrafe a prática, em tese, do crime previsto no art. 33, caput, da Lei n ${ }^{\circ} 11343 / 06$, por ter o mesmo, no dia 26 de abril de 2014, por volta das 19 horas e 30 minutos, na Rua XXX, próximo ao n⿳2 275, bairro XXX, nesta cidade, trazido consigo, para fins de tráfico, 08 (oito) invólucros plásticos contendo 'cocaína', com peso total aproximado de 3,4g (três gramas e quatro decigramas), sem a devida autorização." (Grifos nossos)
\end{abstract}

Sobre a autoria do crime, o MP afirma que ela "restou cabalmente demonstrada diante dos depoimentos das testemunhas, em que pese a negativa do denunciado." (Grifos nossos)

“[...] o acusado negou a prática do crime que lhe foi imputado, alegando que teria se dirigido ao local de sua prisão para adquirir drogas para seu consumo [...]”. (Grifos nossos)

"Destarte, tendo em vista os depoimentos testemunhais, aliados à prova material, não há dúvidas de que o denunciado estava envolvido no exercício da traficância, conforme as diversas denúncias recebidas pela Polícia Militar, pelo que merece integral acolhimento a pretensão punitiva." (Grifos nossos)

\section{Defesa:}

"Narram os autos que R.C.S. foi denunciado por suposta infração do artigo 33 da Lei 11.342/06, porque em tese em data de em data de 26 de abril de 2014, na Rua XXX, próximo ao $\mathrm{n}^{\circ} 275$, Bairro XXX, nesta cidade, possuía e mantinha sobre sua guarda, porções de droga para fins de tráfico." (Grifos nossos)

"O que se observa no presente processo são informações cruzadas e preconceituosas visando demonstrar uma situação fática inexistente." (Grifos nossos) 
"Registre-se que o denunciado admitiu ser usuário e, de forma tácita, que a droga arrecada seria comprada das mãos de S.L.” (Grifos nossos)

No primeiro enunciado da peça acusatória, a dúvida levantada sobre a prática do crime de tráfico de drogas, suscitada pelo uso da expressão "em tese", é superada em todo o restante da narrativa, tanto pela adoção das técnicas já expostas acima, quanto pelas escolhas lexicais operadas pelo locutor e que buscam confirmar sua versão dos fatos: de que o réu praticou o crime de tráfico de drogas. Já no primeiro enunciado vemos essa estratégia se delineando na apresentação de informações precisas sobre onde, quando e por que os eventos ocorreram, somadas à exatidão na descrição da quantidade de drogas, buscando conferir verossimilhança e completude à narrativa. Nesse sentido, podemos afirmar que o uso da expressão "em tese", no início das alegações finais da acusação, procura apenas cumprir uma formalidade jurídica, atendendo às relações de poder presentes nas interações nos tribunais, ao criar o efeito de sentido de que cabe às partes a apresentação dos fatos e apenas ao juiz julgar.

Assim, se tomarmos a afirmação de Coulthard e Johnson (2007, p. 99), citando Cotterill (2003, p. 65ff), de que as escolhas lexicais na construção das narrativas da acusação e da defesa exercem um papel estratégico, pois podem representar os atores e suas ações de modo positivo ou negativo, modelando essas versões da história, percebemos como, nos demais enunciados da acusação e da defesa, a seleção lexical se reveste de forte caráter persuasivo.

Assim, verifica-se que a acusação procura adotar palavras e expressões que conferem certeza a sua versão (restou cabalmente demonstrada, depoimentos testemunhais, aliados à priva material, não há dúvidas [sobre] o exercício da traficância, diversas denúncias recebidas pela Polícia Militar) e dúvida à versão oposta (alegando, teria).

Essa estratégia se repete na narrativa da defesa. Com o intuito de assegurar a verossimilhança de sua versão dos eventos, a defesa adota o verbo "admitiu", para se referir à ação do réu ao se declarar usuário de drogas, e a expressão adverbial "de forma tácita", para confirmar a certeza de sua declaração sobre o fato de estar no local para comprar drogas do menor. Ao mesmo tempo, buscando atacar a narrativa alheia, levantando dúvidas sobre ela, a defesa utiliza-se das seguintes palavras e expressões: em tese, suposta infração, porções de droga (essa escolha por não se referir à quantidade de drogas apreendida é interessante, já que, muitas vezes, o montante de entorpecentes encontrado é determinante para enquadrar a ação do indivíduo em tráfico ou uso), cruzadas e preconceituosas (para se referir às informações testemunhais), inexistente (levantando dúvidas sobre o que seria fato).

\subsection{NEGOCIAÇÃO DA IMAGEM E DO RELACIONAMENTO}

Defesa:

\footnotetext{
"Em que pese o brilhantismo das alegações do ilustre Representante do Ministério Público, não pode a defesa concordar com tal requerimento [...]".
} 
"Ilustre Magistrado, [...]".

"Em um recente julgado dessa douta vara, Vossa Excelência, muito sabiamente [...]".

Em relação à negociação da imagem e do relacionamento, encontramos apenas na peça da defesa enunciados que lançam mão desta técnica argumentativa, ainda que saibamos se tratar de algo comum nos tribunais, devido às formalidades que regulam as interações nos ambientes forenses. No caso do primeiro enunciado, antes de atacar a narrativa da acusação, a defesa ressalta o "brilhantismo" das alegações do representante do Ministério Público, qualificado como "ilustre", buscando a preservação do relacionamento, ainda que o conteúdo de seu dizer vá ser questionado.

Os dois enunciados seguintes, por sua vez, dirigem-se ao juiz, qualificando-o como "ilustre", a vara em que atua como "douta" e uma decisão tomada recentemente por ele como "sábia". Além disso, adota-se o pronome de tratamento "Vossa Excelência", criando um ambiente de respeito e até mesmo de admiração pela figura do magistrado.

\subsection{INCLUSÃO OU APAGAMENTO DE FATOS OU DE VOZES QUE SUSTENTAM DETERMINADO LADO}

Acusação:

Apaga o depoimento da Conselheira Tutelar que confirmou possuir o menor, S.L., várias passagens policiais por tráfico de drogas.

Também não faz nenhuma menção às provas documentais apresentadas pela defesa.

Defesa:

"Certo é que indica-se o maior porque o mesmo tem possibilidade de ficar preso, já que em relação ao adolescente, além de ter várias passagens por tráfico, conforme narrado pela conselheira tutelar M., sabemos que é difícil a internação em centros socioeducativos, ante a falta de vagas."

Por fim, em relação à última estratégia argumentativa utilizada pelas partes, temos, por parte da acusação, a exclusão do depoimento da conselheira tutelar e das provas documentais, de sua narrativa, já que ambos confirmam a narrativa da defesa sobre o envolvimento do menor com o tráfico de drogas e a dependência química do réu. E, por razões óbvias, a defesa, por sua vez, como vimos, por diversas vezes apela para esses documentos como estratégia de produção de evidências e inclui o depoimento da conselheira tutelar em sua narrativa. 
Nosso objetivo neste trabalho foi analisar as estratégias argumentativas adotadas pelas partes - acusação e defesa - nas narrativas de suas alegações finais em um processo criminal de tráfico de drogas. Para tanto, inscrevemos nosso estudo no campo da Linguística Forense, mais especificamente da análise do discurso forense, cujos pressupostos buscam compreender como a produção linguística nos tribunais é influenciada pelos valores e regras institucionais e sociais.

Considerando essas colocações e, mais, que as narrativas na escrita jurídica são um elemento integrante da argumentação legal (HENDERSON, 2015), buscamos, por meio das categorias linguísticas que funcionam como estratégias argumentativas nas peças analisadas, compreender como se deu a representação conflitante da realidade secundária pelas partes, com o intuito de persuadir o magistrado a tomar determinada decisão. Essas estratégias argumentativas possuem dupla função persuasiva: convencer o juiz acerca da completude, verossimilhança e coerência da própria narrativa e, ao mesmo tempo, atacar a narrativa oposta.

Ademais, buscando inserir o texto em suas condições de produção, demonstramos em nossa análise como as regras de interação nos tribunais - altamente hierárquicas, autoritárias e regidas pelas relações de poder entre os participantes - e as crenças sociais dos sujeitos modelam a construção narrativa de suas versões dos fatos.

\section{REFERÊNCIAS}

BAKHTIN, M. Os gêneros do discurso. In: Estética da criação verbal. São Paulo: Martins Fontes, 1977. BRASIL (2006). Lei 11.343, de 23 de agosto de 2006. Brasília: Senado Federal, 2006. Disponível em: <http://www.planalto.gov.br/ccivil_03/_ato2004-2006/2006/lei/111343.htm>. Acesso em: 4 jan. 2015.

BRENTEL, C. As provas não repetíveis no processo penal brasileiro. 2012. $110 \mathrm{f}$. Dissertação (Mestrado em Direito) - Faculdade de Direito da Universidade de São Paulo, São Paulo, 2012.

CALDAS-COULTHARD, C. R. Da análise do discurso à análise crítica do discurso: introduzindo conceitos. In: __ _ SCLIAR-CABRAL, L. (Org.). Desvendando discursos: conceitos básicos. Florianópolis: UFSC, 2008. p. 19-44.

COULTHARD, M.; JOHNSON, A. Introducing forensic linguistics. London; New York: Routledge, 2007.

FIORIN, J. L. Argumentação. São Paulo: Contexto, 2016.

GIBBONS, J. Forensic linguistics: an introduction to language in the justice system. Oxford: Blackwell Publishing, 2003.

HENDERSON, G. Creating legal worlds: story and style in a culture of argument. Toronto: University of Toronto Press, 2015.

HENRIQUES, A. Argumentação e discurso jurídico. São Paulo: Atlas, 2008.

MARCUSCHI, L. A. Gêneros textuais: definição e funcionalidade. In: DIONISIO, A. P.; MACHADO, A. R.; BEZERRA, M. A. Gêneros textuais \& ensino. 3. ed. Rio de Janeiro: Lucerna, 2005. p.19-36.

OLSSON, J; LUCHJENBROERS, J. Forensic Linguistics. London; New Delhi; New York; Sydney: Bloomsbury, 2013.

ROSULEK, L. F. Prosecution and defense closing speeches: the creation of contrastive closing arguments. In: COULTHARD, M.; JOHNSON, A. (Eds.). The Routledge handbook of forensic linguistics. London and New York: Routledge, 2010. p. 218-230.

VALVERDE, A. da G. M.; FETZNER, N. L. C.; TAVARES JÚNIOR, N. C. Lições de linguagem jurídica: da interpretação à produção do texto. 2. ed. Rio de Janeiro: Forense, 2013. 
Recebido em 26/01/17. Aprovado em 25/07/17.

Title: Conflicting versions: argumentative strategies in narratives of prosecution and defense closing speeches

Authors: Carla Leila Oliveira Campos; Sara Sophia Oliveira Vieira

Abstract: The present paper aims at analyzing the techniques of persuasion used by prosecution and defense closing speeches, in a drug trafficking court trial. Interactions in the courts are highly competitive and the use of these argumentative techniques is intended not only to present a more coherent and compelling narrative, but also to attack the opposite narrative in order to persuade the judge in his/her decision-making. Trough Forensic Linguistics studies (COULTHARD; JOHNSON, 2007; GIBBONS, 2003; ROSULEK, 2010), the analysis is organized around the identification of argumentative strategies of the lawyers (linguistic analysis), trying to understand how these narratives are related to primary reality of courts, considering the production conditions of discourse and the socio-historical context in which it emerges.

Keywords: Argumentation. Forensic Linguistics. Narratives. Criminal court trial. Closing Speeches.

Título: Versiones conflictantes: estrategias argumentativas en narrativas de observaciones finales de acusación y de defensa

Autoras: Carla Leila Oliveira Campos; Sara Sophia Oliveira Vieira

Resumen: Este artículo tiene el objetivo de analizar las técnicas de persuasión adoptadas por la acusación y la defensa en sus observaciones finales en un procedimiento judicial por narcotráfico. Las interacciones en los tribunales son altamente competitivas, y el uso de esas técnicas argumentativas tienen no solo el objetivo de presentar una narrativa coherente y convincente, pero al ataque a la narrativa de la otra parte, buscando persuadir el magistrado a la toma de determinada decisión. Basado en estudios de la Lingüística Forense (COULTHARD; JOHNSON, 2007, GIBBONS, 2003; ROSULEK, 2010), el análisis presentada se organiza bajo la identificación de las estrategias argumentativas adoptadas por las partes (análisis lingüístico) y de la comprensión de como las narrativas se relacionan con la realidad primaria de los tribunales, considerando las condiciones de producción del discurso y el contexto socio-histórico de su emergencia.

Palabras-clave: Argumentación. Lingüística Forense. Narrativa. Procedimiento criminal. Observaciones finales.

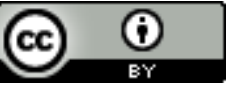

Este texto está licenciado com uma Licença Creative Commons Atribuição 4.0 Internacional.

CAMPOS, Carla Leila Oliveira; VIEIRA, Sara Sophia Oliveira. A disputa pelo sentido nos tribunais: estratégias argumentativas em narrativas de alegações finais da acusação e da defesa. Linguagem em (Dis)curso - LemD, Tubarão, SC, v. 17, n. 3, p. 331-348, set./dez. 2017. 